\title{
Accessing Frustrated Lewis Pair Chemistry through Robust Gold@N- Doped Carbon for Selective Hydrogenation of Alkynes
}

\author{
Jhonatan Luiz Fiorio, ${ }^{\dagger}$ Renato Vitalino Gonçalves, ${ }^{\ddagger \odot}$ Erico Teixeira-Neto, ${ }^{\S}$ Manuel A. Ortuño, ${ }^{\| \odot}$ \\ Núria López, ${ }^{\| \odot}$ and Liane Marcia Rossi*,†॰
}

\author{
†Departamento de Química Fundamental, Instituto de Química, Universidade de São Paulo, Av. Prof. Lineu Prestes, 748, 05508-000 \\ São Paulo, São Paulo, Brazil \\ ${ }^{\ddagger}$ Instituto de Física de São Carlos, Universidade de São Paulo, CP 369, 13560-970 São Carlos, São Paulo Brazil \\ ${ }^{\S}$ Brazilian Nanotechnology National Laboratory (LNNano), Brazilian Center for Research in Energy and Materials (CNPEM), \\ 13083-970 Campinas, São Paulo, Brazil \\ "Institute of Chemical Research of Catalonia, ICIQ, The Barcelona Institute of Science and Technology (BIST), Av. Països Catalans \\ 16, 43007, Tarragona, Spain
}

\section{Supporting Information}

ABSTRACT: Pyrolysis of $\mathrm{Au}(\mathrm{OAc})_{3}$ in the presence of 1,10 phenanthroline over $\mathrm{TiO}_{2}$ furnishes a highly active and selective $\mathrm{Au}$ nanoparticle (NP) catalyst embedded in a nitrogen-doped carbon support, Au@N-doped carbon $/ \mathrm{TiO}_{2}$ catalyst. Parameters such as pyrolysis temperature, type of support, and nitrogen ligands as well as $\mathrm{Au} /$ ligand molar ratios were systematically investigated. Highly selective hydrogenation of numerous structurally diverse alkynes proceeded in moderate to excellent yield under mild conditions. The high selectivity toward the industrially important alkene substrates, functional group tolerance, and the high recyclability makes the catalytic system unique. Both high activity and selectivity are correlated with a frustrated Lewis pairs interface formed by the combination of gold and nitrogen atoms of $\mathrm{N}$-doped carbon that,

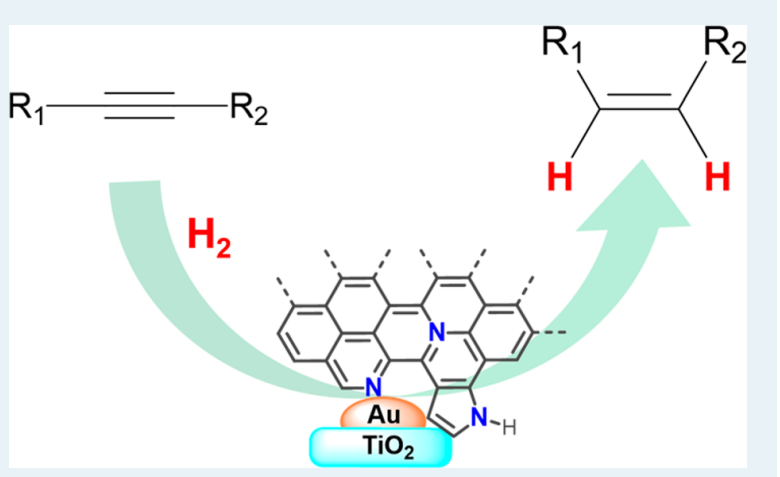
according to density functional theory calculations, can serve as a basic site to promote the heterolytic activation of $\mathrm{H}_{2}$ under very mild conditions. This "fully heterogeneous" and recyclable gold catalyst makes the selective hydrogenation process environmentally and economically attractive.

KEYWORDS: gold, N-doped carbon, hydrogenation, alkyne, heterolytic cleavage, frustrated Lewis pairs

\section{INTRODUCTION}

Alkenes have an extensive range of applications from intermediates in the chemical industry to their primary use as comonomers in the production of polymers. High-purity alkene feedstocks (alkyne free) for the polymer industry are obtained by a very fine-tuned catalytic hydrogenation process; the challenging selective hydrogenation of impurities (alkyne to alkene), while inhibiting the hydrogenation of the alkene to the alkane step and double-bond isomerization. ${ }^{1}$ The semihydrogenation of alkynes to alkenes is also known as a valuable synthetic strategy for drug design. ${ }^{2}$ Typically, platinum group metal catalysts are very active for hydrogenations, but they usually suffer from the lack of selectivity to alkenes., Approaches to improve the chemoselectivity relied on addition of ligands, ${ }^{5,6}$ usually nitrogen, phosphorus, sulfur, or addition of a second less-active metal. ${ }^{7,8}$ In the context of hydrogenations, gold was less explored, ${ }^{9,10}$ but is expected to be intrinsically selective for hydrogenation of triple bonds in alkyne-alkene mixtures, because of the preferential adsorption of only one of these components, the alkyne. ${ }^{11}$ Nevertheless, gold-based catalyst still suffer from the lack of activity, mainly due to limited capability to dissociate molecular hydrogen $\left(\mathrm{H}_{2}\right)$, which usually is the rate-limiting step. ${ }^{3}$ Cooperation between the coordinatively unsaturated $\mathrm{Au}$ atoms on the $\mathrm{Au}$ NPs and the acid-base pair site on $\mathrm{Al}_{2} \mathrm{O}_{3},{ }^{12,13}$ basic sites on hydroxyapatite $^{14,15}$ and on ceria ${ }^{16,17}$ has been suggested as a strategy for the $\mathrm{H}_{2}$ dissociation to yield a $\mathrm{H}^{+} / \mathrm{H}^{-}$pair at the metal-support interface, which is then transferred to the organic moiety. Such heterolytic $\mathrm{H}_{2}$ splitting has been proposed to occur on pure oxides, ${ }^{18-20}$ on gold complexes, ${ }^{21-23}$ or due to a cooperation between gold and adsorbed basic ligands. ${ }^{24-30}$ We have recently systematically studied the activation of gold via the heterolytic dissociation of $\mathrm{H}_{2}$ based on the adsorption of nitrogen-containing bases on gold surfaces. ${ }^{24}$ The activation of $\mathrm{H}_{2}$ was proposed to occur at the metal-ligand interface forming a tight ion pair induced by a frustrated Lewis pair (FLP) like structure, ${ }^{31-35}$ which was able to promote the 
heterolytic activation of $\mathrm{H}_{2}$, allowing a high activity and selectivity for the hydrogenation of alkynes into alkenes. In the proposed mechanism, identified by density functional theory (DFT), the $\mathrm{H}_{2}$ molecule splits forming a quaternary $\mathrm{N}$ center (amine protonation) and a hydride on the gold surface; both $\mathrm{H}^{-}$and $\mathrm{H}^{+}$were then transferred to the organic moiety in a synfashion controlled by electrostatic interactions.

Nitrogen-doped carbon materials affect the catalytic activity and selectivity of transition metals significantly, such as cobalt,$~^{36,37}$ nickel, $^{38}$ palladium, ${ }^{39,40}$ ruthenium, ${ }^{41}$ and iron/ iron oxide-based catalysts. ${ }^{42,43}$ The incorporation of nitrogen atoms in the carbon architecture combined with metal nanoparticles have enabled application in a wide range of catalytic reactions including reductions, oxidations, and $\mathrm{H}_{2}$ generation. ${ }^{44,45} \mathrm{~N}$-Doped carbon structures have also emerged as an important component of catalysts for hydrogenation reactions. ${ }^{36,42,46,47}$ More interestingly, a heterolytic $\mathrm{H}_{2}$ activation has been invoked to explain the hydrogenation reaction mechanism. ${ }^{48-50}$ Although it is not explicit in the previous studies, it is likely that the metal-N-doped carbon interface can be understood as a FLP, with an active participation of the support basic nitrogen atoms in the $\mathrm{H}_{2}$ activation. Based on our interest in this concept, we decided to explore the synthesis of gold nanoparticle catalysts embedded on $\mathrm{N}$-doped carbon for studies in selective hydrogenations. The main advantage with respect to previous studies ${ }^{24}$ is to avoid the addition of external ligands, in large excess, for the activation of gold surfaces via FLP, making the whole process environmentally and economically attractive.

\section{RESULTS AND DISCUSSION}

We commenced our study by preparing a series of gold catalysts inspired by the method developed by Beller's group for the preparation of $\mathrm{Ni}, \mathrm{Co}$, and Fe-catalysts. ${ }^{36,42,47,51,52}$ The gold catalysts were prepared by pyrolysis of the gold precursor at different temperatures in the range from 200 to $800^{\circ} \mathrm{C}$ in the presence of 1,10-phenantroline (L1) and $\mathrm{TiO}_{2}$ support under $\mathrm{N}_{2}$ atmosphere (Figure S1). The thermal behavior TG-DTG of the $\mathrm{Au}-\mathrm{L} 1 / \mathrm{TiO}_{2}$ material under $\mathrm{N}_{2}$ indicated that the pyrolysis proceeds in a multistage fashion (Figure S2). We studied the influence of the pyrolysis temperature on the catalytic activity of the various materials obtained for the benchmark hydrogenation of phenylacetylene 1a using molecular hydrogen $\left(\mathrm{H}_{2}\right)$ (Table 1). The material pyrolyzed at $200{ }^{\circ} \mathrm{C}$ lead to $51 \%$ of

Table 1. Catalytic Activity in the Hydrogenation of Phenylacetylene of Au@N-Doped Carbon Catalysts Obtained from Au-L1/ $\mathrm{TiO}_{2}$ after Pyrolysis at Different Temperatures $^{a}$

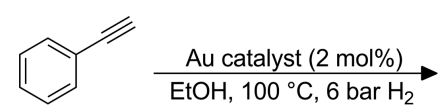

$1 \mathrm{a}$

$\begin{array}{cccc}\text { entry } & \text { pyrolysis temperature }\left({ }^{\circ} \mathrm{C}\right) & \text { conversion of } \mathbf{1 a}(\%) & \text { yield of } \mathbf{2 a}(\%) \\ 1 & 200 & 51 & >99 \\ 2 & 400 & 100 & >99 \\ 3 & 600 & 27 & >99 \\ 4 & 800 & 5 & 65\end{array}$

${ }^{a}$ Reaction conditions: 0.14 mmol 1a, 2 mol \% of Au@N-doped catalyst, $2 \mathrm{~mL}$ of ethanol, $100{ }^{\circ} \mathrm{C}, 6 \mathrm{bar} \mathrm{H}_{2}, 20 \mathrm{~h}$. Conversion and yield determined by GC using internal standard technique. conversion of 1a (Table 1, entry 1 ). The best activity was obtained by performing the pyrolysis at $400{ }^{\circ} \mathrm{C}$ (Table 1 , entry 2). On increasing the pyrolysis temperature to 600 and $800{ }^{\circ} \mathrm{C}$, the activity of the resulting catalyst decreased significantly (Table 1, entries 3 and 4). We next studied the influence of the $\mathrm{N}$-containing ligands on the stabilization and catalytic activity of the various materials obtained after pyrolysis at $400{ }^{\circ} \mathrm{C}$ (Table 2).

Table 2. Catalytic Activity in the Hydrogenation of Phenylacetylene of Au@N-Doped Carbon Catalysts Obtained with Different N-Containing Ligands, after Pyrolysis at $400{ }^{\circ} \mathrm{C}^{a}$

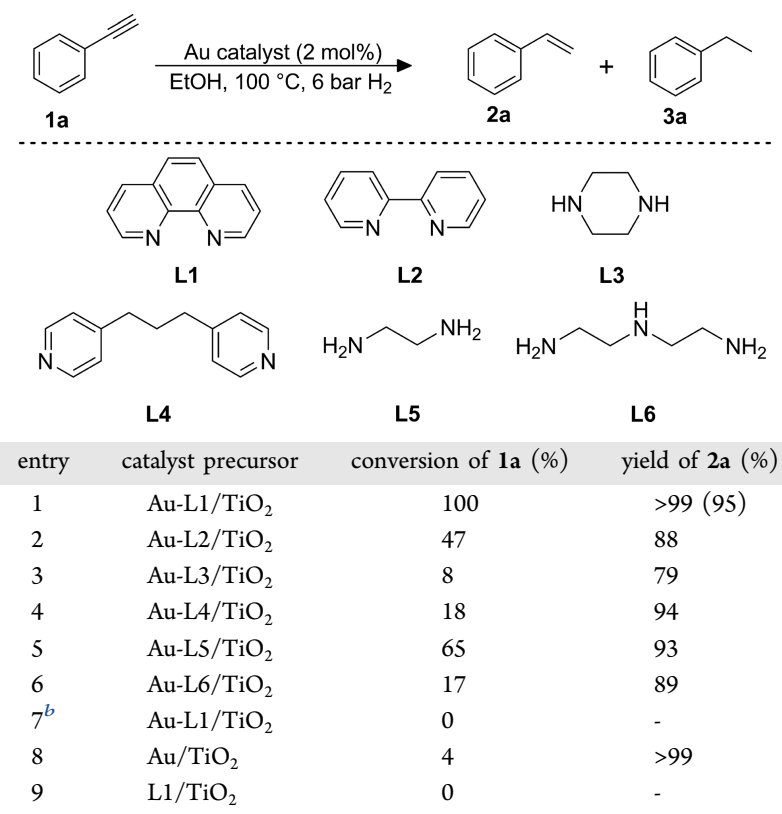

${ }^{a}$ Reaction conditions: $0.14 \mathrm{mmol}$ of $1 \mathrm{a}, 2 \mathrm{~mol} \%$ of Au catalyst, $2 \mathrm{~mL}$ of ethanol, $100{ }^{\circ} \mathrm{C}, 6$ bar of $\mathrm{H}_{2}, 20 \mathrm{~h}$. Conversion and yield determined by GC using internal standard technique; numbers in parentheses refer to isolated yield. ${ }^{b}$ Catalyst not pyrolyzed.

Among the different N-containing ligands tested, 1,10phenanthroline ( $\mathrm{L} 1)$ was found to give the most-active system (Table 2, entry 1), resulting in a catalyst that exhibited superior reactivity in comparison with those obtained from other ligands such as $2,2^{\prime}$-bipyridine (L2), ethylenediamine (L5), diethylenetriamine (L6) (Table 2, entries 2, 5, and 6). The catalyst obtained using piperazine (L4) showed the lowest activity (Table 2, entry 3). Moreover, the model reaction does not occur to any extent in the presence of the material not submitted to pyrolysis (Table 2, entry 7). Notably, the catalyst prepared without addition of any ligand $\left(\mathrm{Au} / \mathrm{TiO}_{2}\right)$ showed significant low catalytic activity (Table 2 , entry 8 ), and no conversion was observed with a material obtained via pyrolysis of the support with 1,10-phenantroline $\left(\mathrm{L} 1 / \mathrm{TiO}_{2}\right)$ but without the gold precursor (Table 2, entry 9). We further investigated the potential effect of supports $\left(\mathrm{C}, \mathrm{CeO}_{2}, \mathrm{MgO}, \mathrm{Fe}_{3} \mathrm{O}_{4}, \mathrm{SiO}_{2}\right.$, and $\mathrm{TiO}_{2}$ ) in the catalytic activity (Table $\mathrm{S} 1$ ). The catalysts based on carbon, cerium oxide, iron oxide, and magnesium oxide showed low conversion $(\leq 10 \%)$. The catalyst supported on silica reaches $71 \%$ of conversion, but the fully hydrogenated product 3a was formed. Titanium dioxide proved to be the best support under the studied conditions. The gold precursor 
influence of the catalytic activity was also evaluated (Table S2). The catalyst prepared using gold acetate showed the best result, full conversion of 1a, and a slight decrease in catalytic activity was noticed when using hydrogen tetrachloroaurate(III) $(68 \%$ of conversion) or potassium dicyanoaurate(I) (90\% of conversion). An increase in the $\mathrm{Au} / \mathrm{L} 1$ molar ratio from $1: 2$ to 1:5 or 1:10 led to complete loss of catalytic activity (Table S3). After a further survey of common reaction parameters (solvent, reaction temperature, molecular hydrogen pressure; for more details, see Tables S4, S5 and S6 at the Supporting Information), the best reaction conditions were ethanol as solvent, 6 bar of $\mathrm{H}_{2}$ at $100{ }^{\circ} \mathrm{C}$. The most active catalytic material obtained by pyrolysis at $400{ }^{\circ} \mathrm{C}$ was characterized in detail. The active catalyst contains $1.1 \mathrm{wt} \% \mathrm{Au}, 0.7 \mathrm{wt} \% \mathrm{C}$ and $0.2 \mathrm{wt} \% \mathrm{~N}$, as determined by elemental analysis and FAAS. Images by scanning transmission electron microscopy (STEM) of the material pyrolyzed with the L1 ligand revealed formation of Au NPs with a mean diameter of $4.5 \mathrm{~nm}$, in addition, a few larger particles of $10 \mathrm{~nm}$ were observed occasionally (Figure $\mathrm{S} 3 \mathrm{a}-\mathrm{c})$. In complete contrast, the catalyst prepared without the presence of the ligand, a significant increase in the gold NPs size was observed, with a mean diameter about $17 \mathrm{~nm}$ (Figure $\mathrm{S} 3 \mathrm{~d}-\mathrm{f}$ ). UV-vis diffuse reflectance spectra were recorded for both solids (with and without L1), showing a typical gold SPR band (Figure S4). The X-ray diffraction (XRD) pattern corresponding to Bragg diffractions of $\mathrm{Au}(200)$ at $44^{\circ}, \mathrm{Au}$ (220) at $65^{\circ}$, or $\mathrm{Au}(311)$ at $78^{\circ}$, confirmed the metal reduction and anatase as the predominant phase, without significant phase conversion after thermal treatment (Figure $\mathrm{S5})$. EDX spectrum imaging (elemental mapping) of the $\mathrm{Au}-$ $\mathrm{L} 1 / \mathrm{TiO}_{2}$ material after pyrolysis at $400{ }^{\circ} \mathrm{C}$ provided a clear evidence for the presence of carbon deposited on the surface of the $\mathrm{Au}$ NPs (Figure 1). No conclusive information on the location of nitrogen in the sample could be obtained because of
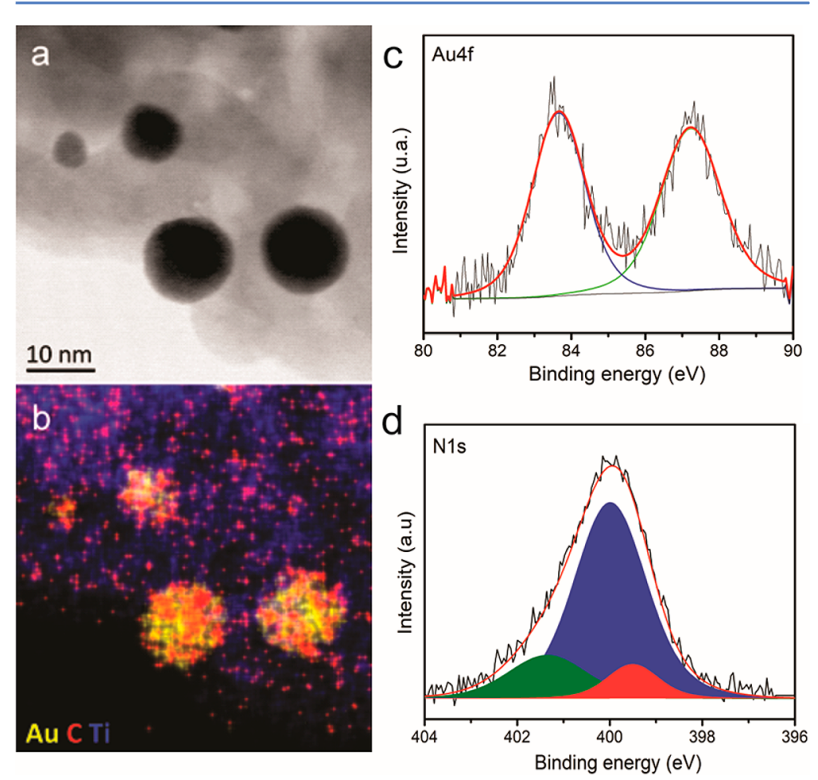

Figure 1. (a) Bright-field STEM image of a representative area of the $\mathrm{Au} @ \mathrm{~N}$-doped carbon/ $/ \mathrm{TiO}_{2}$ catalyst $\left(\mathrm{Au}-\mathrm{L} 1 / \mathrm{TiO}_{2}\right.$ material after pyrolysis at $400{ }^{\circ} \mathrm{C}$ ) and (b) corresponding EDX elemental maps. Carbons appear as the red spots deposited mostly on the yellow gold particles. (c) Au $4 f$ XPS spectrum and (d) N 1s XPS spectrum for the $\mathrm{Au} @ \mathrm{~N}$-doped carbon $/ \mathrm{TiO}_{2}$ catalyst. the overlap of the majoritarian $\mathrm{Ti}$ signal at $0.452 \mathrm{keV}$ with the $\mathrm{N}$ signal at $0.392 \mathrm{keV}$ (Figure S6).

The type of $\mathrm{N}$-doping was investigated in more detail by $\mathrm{X}$ ray photoelectron spectroscopy (XPS). The XPS survey spectrum of catalytic material obtained by pyrolysis at $400{ }^{\circ} \mathrm{C}$ revealed that the samples surface contains $\mathrm{Au}, \mathrm{C}, \mathrm{Ti}, \mathrm{N}$, and $\mathrm{O}$. The $\mathrm{Au}$ if spectrum exhibit two peaks centered at binding energy 87.0 and $83.3 \mathrm{eV}$, which correspond to the $\mathrm{Au}^{0}$ oxidation state ${ }^{53,54}$ (Figure 1c). Valuable information was obtained by analysis of the binding energy peak of the $\mathrm{N} 1 \mathrm{~s}$ region (Figure 1d and Figure S7-S9). The N 1s spectrum of the most active Au@N-doped carbon catalyst (pyrolysis at 400 ${ }^{\circ} \mathrm{C}$ ) was fitted with three components located at binding energies of 399.5, 400, and $401.3 \mathrm{eV}$ (Figure 1d). The peak at $401.3 \mathrm{eV}$ can be attributed to graphitic nitrogen, while the peak at $399.5 \mathrm{eV}$ can be attributed to the pyridinic nitrogen species. ${ }^{44,55,56}$ However, the peak at $400 \mathrm{eV}$ is more difficult to attribute, as it can be both a result of $\mathrm{Au}-\mathrm{N}$ interaction (see results for $\mathrm{Au}-\mathrm{L} 1 / \mathrm{TiO}_{2}$ (before pyrolysis), Figure S9) or due to pyrrolic nitrogen species, very often present in $\mathrm{N}$-doped carbon systems, ${ }^{46}$ and also present in the XPS $\mathrm{N}$ 1s spectrum of the sample $\mathrm{L} 1 / \mathrm{TiO}_{2}$ (without gold) (Figure S7). This component at ca. $400 \mathrm{eV}$ was found in all catalysts prepared by pyrolysis with other ligands (L2-L6) at $400{ }^{\circ} \mathrm{C}$ (Figure S8) and for $\mathrm{Au} /$ $\mathrm{L} 1-\mathrm{TiO}_{2}$ at other pyrolysis temperatures (Figure S9). The asprepared catalyst precursor $\mathrm{Au}-\mathrm{L} 1 / \mathrm{TiO}_{2}$ (before pyrolysis) displays two nitrogen species at 399.3 and $399.8 \mathrm{eV}$ (Figure S9), which are tentatively attributed to pyridinic nitrogen atoms of free ligand and of the ligand coordinated and/or adsorbed on gold $(\mathrm{Au}-\mathrm{N})$, respectively. The 1,10-phenanthroline ligand adsorbed on $\mathrm{TiO}_{2}\left(\mathrm{~L} 1 / \mathrm{TiO}_{2}\right.$ without gold) displays only one nitrogen species at $399.4 \mathrm{eV}$ (Figure S7), typically of a pyridinic nitrogen atom (free ligand).

The kinetic study shown in Figure $2 b$ indicates full conversion of $1 \mathrm{a}$ to $2 \mathrm{a}$ in about $8 \mathrm{~h}$ and suppression of further hydrogenation of $\mathbf{2 a}$ to $\mathbf{3 a}$, even at long reaction times. This high selectivity for the alkene $2 a$ is an intrinsic property of our catalyst and it was not observed for the well-known Pd Lindlar catalyst $\left(\mathrm{Pd} / \mathrm{CaCO}_{3}+\mathrm{Pb}\left(\mathrm{OCOCH}_{3}\right)_{2}+\right.$ quinoline $)$, which produces $3 \mathbf{a}$ at high conversions (Figure S10). It is worthwhile to note that a sixty-fold reaction rate enhancement was observed when comparing the catalytic activity of similar $\mathrm{Au}$ catalysts prepared with L1 (Figure 2b) (reaction rate $=0.273$ $\mathrm{mmol} \mathrm{g} \mathrm{cat}^{-1} \mathrm{~h}^{-1}$ ) or without any ligand (Figure $2 \mathrm{c}$ ) (reaction rate $\left.=0.00472 \mathrm{mmol} \mathrm{g}_{\mathrm{cat}}{ }^{-1} \mathrm{~h}^{-1}\right)$. In order to further examine the stability as well as recyclability of the "fully heterogeneous" catalytic material, the hydrogenation of 1a was repeated up to 10 times using the same catalyst portion without any further treatment or ligand addition. As depicted in Figure $2 \mathrm{~d}$, the desired product styrene $2 \mathrm{a}$ was obtained in a $99 \%$ yield even after ten runs and no significant loss of activity was observed (see also Figure S11). A hot filtration test (Figure 2e) revealed that the obtained activity is not related to any leaching of the catalytically active metal (no remaining activity in the supernatant). ICP AES analysis of the recycling experiments indicated no undesired leaching processes of gold occurred during the course of the catalytic transformation. Furthermore, no aggregation of Au NPs was observed by STEM of the recycled catalyst after the 10th recycle (Figure S12).

Because Au@N-doped carbon $/ \mathrm{TiO}_{2}$ catalyst $\left(\mathrm{Au}-\mathrm{L} 1 / \mathrm{TiO}_{2}\right.$ pyrolyzed at $400{ }^{\circ} \mathrm{C}$ ) displayed the best activity for the production of styrene, it was explored in the scope study under the optimized conditions. A variety of terminal and internal 

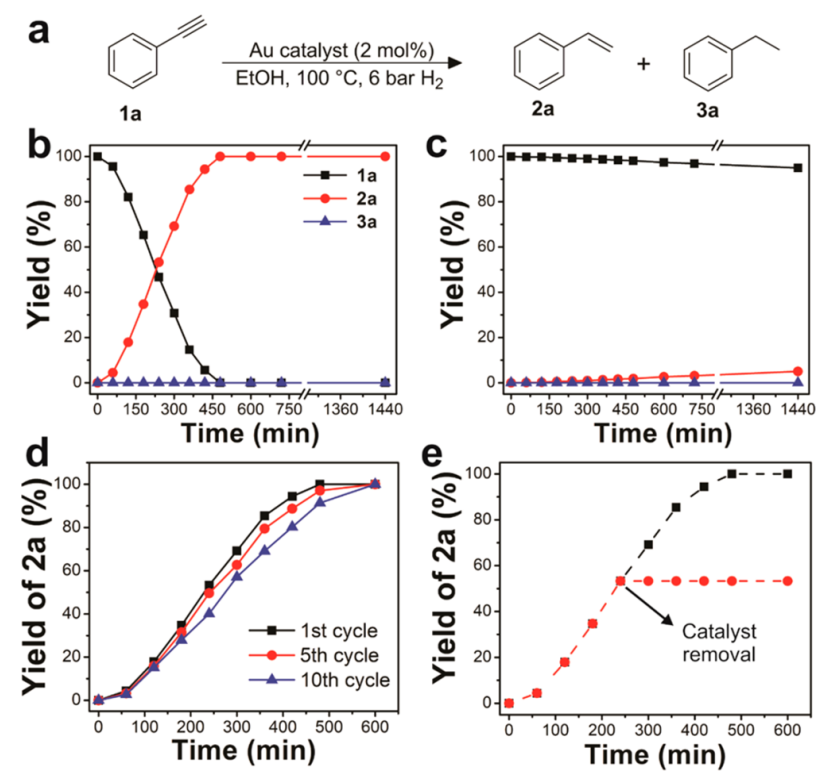

Figure 2. (a) Time course of hydrogenation of phenylacetylene 1a catalyzed by (b) $\mathrm{Au} @ \mathrm{~N}$-doped carbon $/ \mathrm{TiO}_{2}$ catalyst and (c) $\mathrm{Au} / \mathrm{TiO}_{2}$ catalyst; (d) recycling experiments and (e) hot filtration test to determine homogeneous catalysis contribution in hydrogenation of $\mathbf{1 a}$. Reaction conditions: $0.14 \mathrm{mmol}$ of $1 \mathrm{a}, 2 \mathrm{~mol} \%$ of $\mathrm{Au}, 2 \mathrm{~mL}$ of ethanol, $100{ }^{\circ} \mathrm{C}, 6$ bar of $\mathrm{H}_{2}$. alkynes was readily hydrogenated to the desired alkene and cisalkene with moderate to excellent yield (Scheme 1) and, notably, different from what occur with other transition metals, without any over-reduction to alkane. Moreover, both electrondeficient substituents, such as esters (2ab) and carboxylic acids (2ad) moieties, and electron-rich groups, for example amino ( $2 s$ and $2 t$ ) and methoxy ( $2 c$ and $2 r$ ), were tolerated well. The developed catalyst was even able to reduce only the alkyne unit in molecules with alkene moieties $(2 \mathbf{k}, 2 \mathbf{v}, 2 \mathbf{w}$, and $2 \mathrm{x})$, without any detectable concurrent reduction of the alkene moieties both in the parent and product molecules. The results depicted in Scheme 1 confirmed that a broad range of sensitive and reducible functional groups, including halide $(2 \mathrm{~d}, 2 \mathrm{e}, 2 \mathrm{p}$, and $\mathbf{2 q})$, ketones $(\mathbf{2 u})$, and aldehydes (2ac), were tolerated in the alkyne hydrogenation process. With an increase in $\mathrm{H}_{2}$ pressure (10 bar $\left.\mathrm{H}_{2}\right),(Z)$-alkenes were mostly formed from internal alkynes $(\mathbf{2 y}-\mathbf{2 a f})$. The catalyst system was also applicable for scaled-up conditions, where $5 \mathrm{mmol}$ of $1 \mathrm{a}(0.51 \mathrm{~g})$ was successfully converted into the alkene 2a (0.49 g, 94\%). Considering full conversion, the turnover number (TON) of 1700 was reached, with a TOF of $70 \mathrm{~mol} \mathrm{~mol}^{-1} \mathrm{~h}^{-1}$. This TOF value is an order of magnitude higher than the values reported for heterogeneous gold-based catalysts using molecular hydrogen as hydride source and without the use of ligands. Furthermore, this TOF is also high when taking into account values for systems using other sources of hydride and ligands to boost the catalytic activity (Table S7).

Scheme 1. Au@N-Doped Carbon/ $\mathrm{TiO}_{2}$ Catalyst for the Semihydrogenation of Alkynes to Alkenes ${ }^{a, b}$
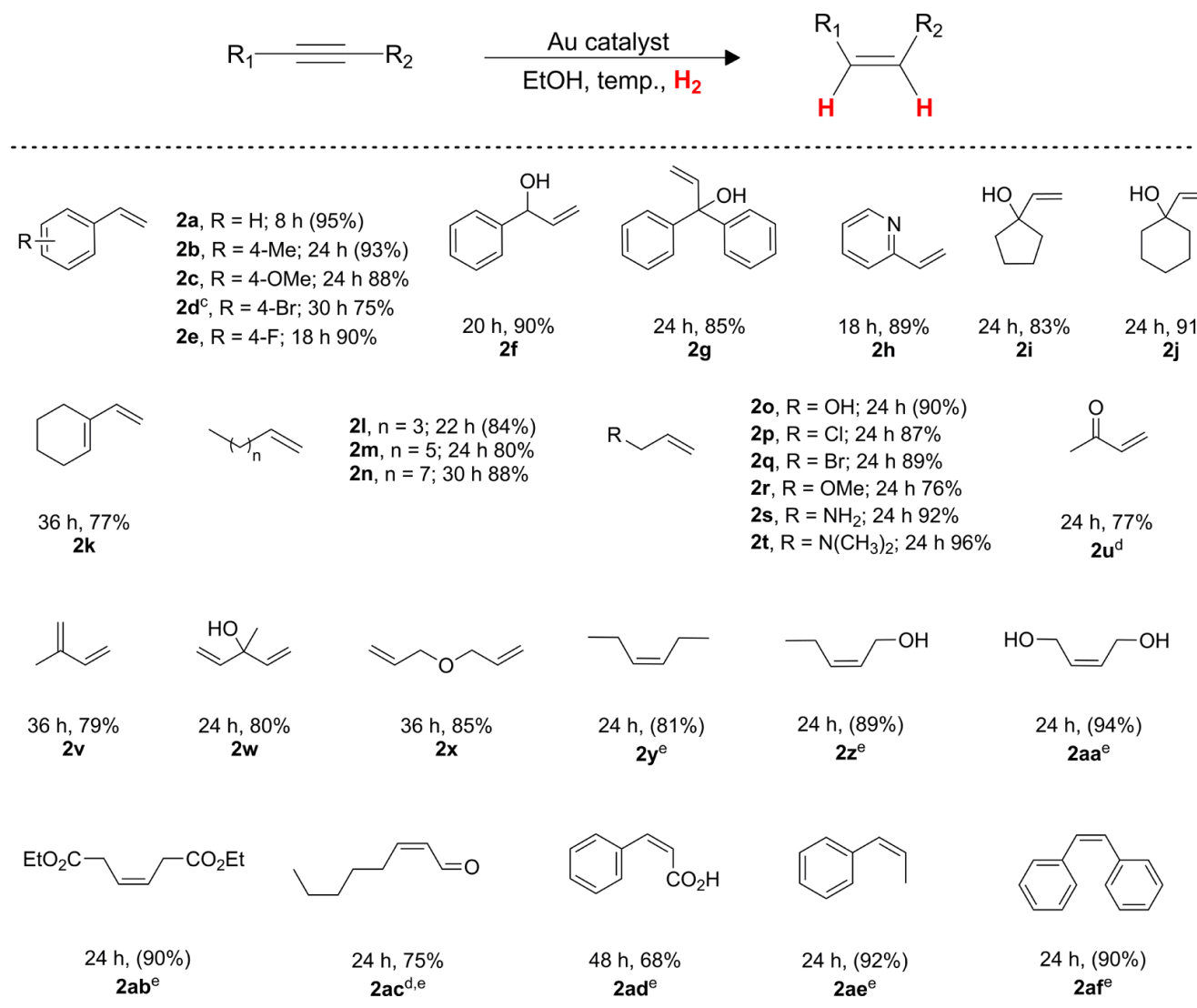

${ }^{a}$ Reaction conditions: $0.14 \mathrm{mmol}$ of alkyne, $2 \mathrm{~mol} \%$ of Au catalyst, $2 \mathrm{~mL}$ of ethanol at $100{ }^{\circ} \mathrm{C}, 6 \mathrm{bar}$ of $\mathrm{H}_{2} \cdot{ }^{b} \mathrm{GC}$ yields are shown; values in parentheses refer to isolated yields. Selectivity was $>99 \%$. ${ }^{c} 8$ bar of $\mathrm{H}_{2} .{ }^{d} 80{ }^{\circ} \mathrm{C} .{ }^{e} 10$ bar of $\mathrm{H}_{2}$. 
To further check the chemoselectivity of the developed catalyst, we performed experiments using $\mathbf{1 a}$ as substrate in the presence of molecules functionalized with other sensitive groups (Scheme 2). Total chemoselectivity was observed for

Scheme 2. Selective Hydrogenation of $1 \mathrm{a}$ in the Presence of Molecules with Other Reducible Functional Groups by Au@ $\mathrm{N}$-Doped Carbon/ $/ \mathrm{TiO}_{2}$ Catalyst $^{a}$

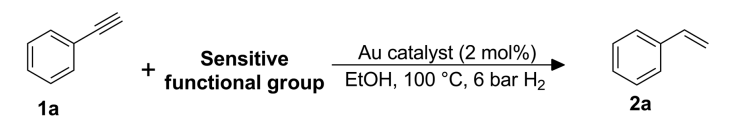

Conversion 1a: $>99 \%$ Conversion sensitive group: $<1 \%$

Tested sensitive functional groups:

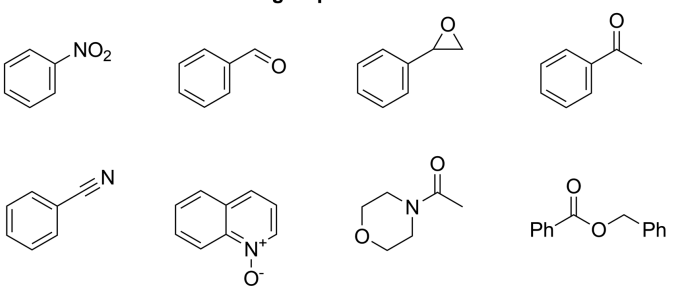

${ }^{a}$ Reaction conditions: $0.14 \mathrm{mmol} 1 \mathrm{a}, 0.14 \mathrm{mmol}$ of sensitive molecule, $2 \mathrm{~mol} \%$ of $\mathrm{Au}$ catalyst, $2 \mathrm{~mL}$ of ethanol, $24 \mathrm{~h}, 100{ }^{\circ} \mathrm{C}, 6 \mathrm{bar} \mathrm{H}_{2}$. Conversion was determined by GC using internal standard technique.

the reduction of the model alkyne in the presence of potentially reducible groups, such as nitro, aldehydes, epoxides, ketones, nitriles, esters, heteroaromatic $\mathrm{N}$-oxides, and amide, because not even traces of conversion of these functional groups were detected. In the absence of the alkyne, some of those functional groups such as epoxides, nitro, aldehydes, heteroaromatic $N$ oxides, and sulfoxides can be efficiently reduced as well (Table S8).

On the basis of the experimental results and previous work, we believe that pyridinic, graphitic, and pyrrolic $\mathrm{N}$ atoms play a pivotal role in boosting the catalytic activity of our gold-based catalyst. The reactivity pattern displayed by the Au@N-doped carbon catalyst, prepared via pyrolysis of $\mathrm{Au}-\mathrm{L} 1 / \mathrm{TiO}_{2}$, allows us to postulate that $\mathrm{H}_{2}$ activation may proceed by a heterolytic pathway, due to the interaction of Au NPs and the nitrogen atoms of the $\mathrm{N}$-doped carbon around the metallic nanoparticles, following the concept of frustrated Lewis pair interface suggested before for Au NPs and externally added $\mathrm{N}$-containing ligands. ${ }^{24}$ This type of $\mathrm{H}_{2}$ activation at $\mathrm{N}$-doped carbon supports was previously described for $\mathrm{Pd}^{48}$ boronnitrogen codoped graphene, ${ }^{57}$ and Co catalyst. ${ }^{49}$ The introduction of $\mathrm{N}$ atoms might affect the properties of the supported catalyst, such as tunable acid-base character at the support surface, which could cause a better interaction of metal-support-reactant, as well as charge transfer phenomena at the metal-support junction. ${ }^{44}$

In order to gain more insight into the mechanism of the reaction, we conducted a Hammett correlation study using the developed catalyst and Lindlar catalyst to verify the influence of various para substituents on aromatic alkynes. The Hammett plot for the reaction catalyzed by Au@N-doped carbon catalyst reveals that the reaction is sensitive to the substituent (Figure $3)$. The reaction rate was enhanced in the presence of electronwithdrawing groups, and the positive value of $\rho\left(\rho=+1.73 ; R^{2}\right.$ $=0.93$ ) highlights the buildup of negative charge during the catalytic cycle. The value of $\rho$ with Lindlar catalysts was close to

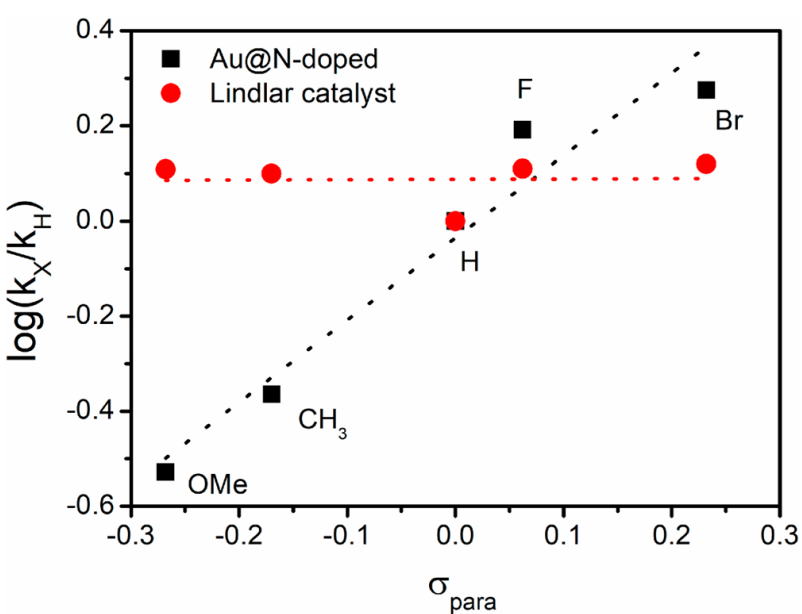

Figure 3. Hammett plot for the hydrogenation of various parasubstituted alkynes catalyzed by $\mathrm{Au} @ \mathrm{~N}$-doped carbon $/ \mathrm{TiO}_{2}$ and Lindlar catalyst.

0 , which indicates a lack of substituent effect in the hydrogenation reaction and that no charge is built or lost during the catalytic cycle. Those results give support to a heterolytic $\mathrm{H}_{2}$ dissociation mechanism for the Au@N-doped carbon catalyst, in contrast to the homolytic $\mathrm{H}_{2}$ activation mechanism for Lindlar catalyst. Moreover, theoretical calculation and experimental results have demonstrated that nitrogen doping structures could also enhance the stability of $\mathrm{Au}$ catalyst against sintering, preserving the catalytic activity $^{54,58,59}$ which explains the high recyclability and lack of particle aggregation.

On the basis of the results described above, we propose that the nitrogen atoms doped on carbon have a major role in the heterolytic activation of $\mathrm{H}_{2}$ via frustrated Lewis pairs. To support such hypothesis, we present a computational study of the hydrogenation mechanism of alkyne 1a. Following previous experiments (Table 2, entry 1), we model a $\mathrm{Au}(111)$ surface functionalized with phenanthroline L1. Taking into account the high coverage situation of the experiments, the $\pi$-system of L1 may adsorb in two main configurations: (i) parallel (flat) to the surface, model A, or (ii) perpendicular to it, model A2. Model A contains one L1 in the supercell, while model A2 can fit up to three (Figure S13). Both situations present the same adsorption energy $\left(E_{\mathrm{ads}}\right)$ per ligand, $(-0.74$ and $-0.75 \mathrm{eV}$, respectively, Table S9), with the shortest $\mathrm{Au} \cdots \mathrm{N}$ distances of ca. 3.3 and 3.5 $\AA$, respectively. At high coverage situations, the packing predicted in model A2 would be expected, and in operando conditions, ligands would be replaced by reactant molecules via $0.75 \mathrm{eV}$. Such a continuous release of ligand compromises the robustness of the catalyst. After pyrolysis treatment, however, aromatic rings agglomerate to form extended graphene-like sheets. From literature we know that the $E_{\mathrm{ads}}$ of benzene on $\mathrm{Au}(111)$ is $0.63 \mathrm{eV}$ (experiment) ${ }^{60}$ and $0.48 \mathrm{eV}$ (theory); ${ }^{61}$ in other words, ca. $0.08 \mathrm{eV}$ per sp $\mathrm{sp}^{2}$ atom. The $E_{\text {ads }}$ of $\mathrm{L} 1\left(14 \mathrm{sp}^{2}\right.$ atoms) on $\mathrm{Au}(111)$ in model $\mathbf{A}$ is 0.74 or $0.05 \mathrm{eV} / \mathrm{sp}^{2}$, somehow smaller than that of benzene. The hypothetical merging of two L1 ligands ( $28 \mathrm{sp}^{2}$ atoms) would render a new species with a significantly larger $E_{\text {ads }}$ of $\sim 1.4 \mathrm{eV}$. In contrast to free ligand conditions, where ligands can be easily displaced, extended graphene-like sheets anchor to the surface, thus creating a stable and robust system while maintaining the nature of the catalytic active site. 
Herein we use model A (Figure 4 inset) to properly mimic the $\mathrm{N}$-doped (pyridinic) graphene-like sheets experimentally

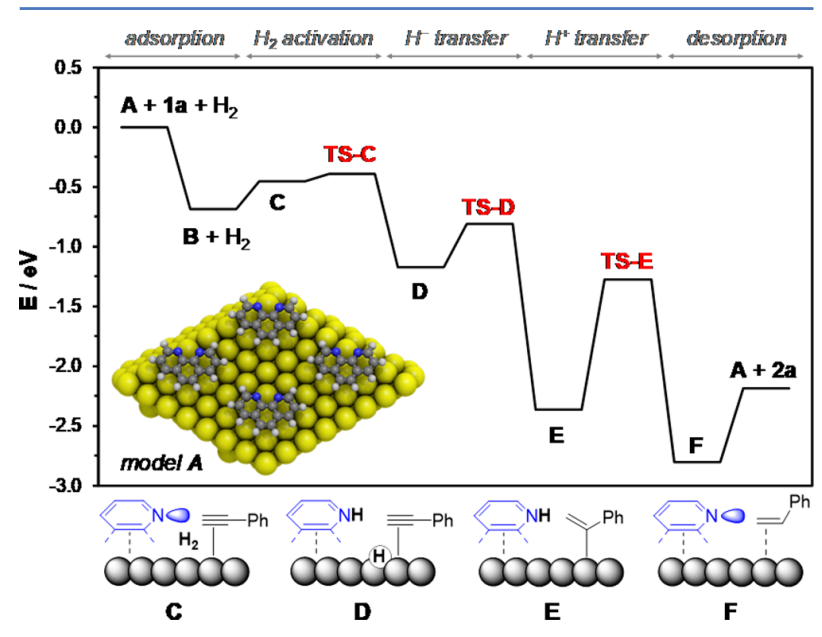

Figure 4. Computed reaction energy profile for the hydrogenation of 1a on L1-functionalized $\mathrm{Au}(111)$ surface ( $\mathrm{Au}=$ yellow, $\mathrm{N}=$ blue, $\mathrm{C}=$ gray, $\mathrm{H}=$ white).

observed after pyrolysis. The proposed reaction mechanism is shown in Figure 4. First, the alkyne 1a interacts with the surface A with an energy of $-0.69 \mathrm{eV}\left(\right.$ B). Although subsequent $\mathrm{H}_{2}$ adsorption (C) is slightly endothermic by $0.23 \mathrm{eV}$, the $\mathrm{N}$ assisted heterolytic $\mathrm{H}_{2}$ activation (TS-C) is essentially barrierless, with a relative energy barrier of $0.07 \mathrm{eV}$ above $\mathbf{C}$ $(0.30 \mathrm{eV}$ above $\mathbf{B})$. Moreover, the formation of $\mathbf{D}$ is significantly exothermic by $0.71 \mathrm{eV}$. These results are in sharp contrast with the $\mathrm{H}_{2}$ dissociation on pristine $\mathrm{Au}(111)$, where the energy barrier is $1.45 \mathrm{eV}$ and the reaction energy is endothermic by $0.69 \mathrm{eV}^{24}$ The absence of a direct interaction between the lone pair of the nitrogen and the gold surface $(\mathrm{Au} \cdots \mathrm{N}$ distances of ca. $3.3 \AA$ ) creates a unique interface that promotes the heterolytic cleavage. In that sense, we can relate this behavior to gold-based FLP chemistry. ${ }^{62}$ Then, the hydride from the surface $\mathbf{D}$ eventually transfers to the alkyne (TS-D) with a barrier of $0.36 \mathrm{eV}$ and forms the alkenyl intermediate E. Final proton transfer from nitrogen to carbon has a barrier of $1.09 \mathrm{eV}$ (TS-E) and produces intermediate F, from which the product 2a quickly desorbs $(0.62 \mathrm{eV})$ and regenerates the initial species A. Overall, the present mechanism is in line with experiments and ilustrates the major role of nitrogen atoms during the $\mathrm{H}_{2}$ activation process.

\section{CONCLUSIONS}

We have prepared, for the first time, a $\mathrm{N}$-doped carbon supported gold-based catalyst that exhibited excellent activity and selectivity for the hydrogenation of alkynes to alkenes, in a broad scope of substrates, at mild reaction condition. The intriguing structure of the novel gold heterogeneous catalyst, which could be understood as frustrated Lewis pairs interfaces according to computational studies, enables the heterolytic activation of molecular hydrogen, boosting gold catalytic activity while avoiding addition of external ligands to improve activity and selectivity. The graphenization of the ligand ensures that it is present on the surface and not removed by the solvent or the reactants, which explains the robustness of the material under reaction conditions. We demonstrated that the heterolytic dissociation of $\mathrm{H}_{2}$ can occur in a fully heterogeneous catalyst, which will be economically and environmentally attractive. The Au@N-doped carbon catalyst tolerates other reducible functional groups, including $\mathrm{C}-\mathrm{C}$ double bonds, nitro, aldehydes, epoxides, ketones, nitriles, esters, heteroaromatic $\mathrm{N}$-oxides, and amides, and they can be recycled without loss of activity. The surface-FLP concept is in its infancy when compared to main group-FLP ${ }^{32,63}$ and transition metal-based FLP ${ }^{64}$ but has shown many interesting features. The expansion of this concept for a broad range of applications in the field of heterogeneous catalysis is encouraged. New reactivity patterns, not limited to activation of $\mathrm{H}_{2}$, will be soon explored.

\section{EXPERIMENTAL SECTION}

Procedure for Preparation of Au-L/Support. Typically, $\mathrm{Au}(\mathrm{OAc})_{3}(19 \mathrm{mg}, 0.05 \mathrm{mmol})$ and amine ligand $(18 \mathrm{mg}, 0.1$ $\mathrm{mmol}$ ) (molar ratio $\mathrm{Au}: L=1: 2$ ) were stirred in $20 \mathrm{~mL}$ of ethanol for approximately $5 \mathrm{~min}$ at $60{ }^{\circ} \mathrm{C}$. The support was then added and the mixture was stirred for more $20 \mathrm{~min}$. Afterward, the solvent was dried by rotary evaporation. The asobtained solid was ground to a fine powder and then pyrolyzed under nitrogen atmosphere in the desired temperature in an oven at a rate of $10^{\circ} \mathrm{C}$ per minute and held at temperature for $2 \mathrm{~h}$.

General Procedure for Hydrogenation of Alkynes. Unless otherwise stated, a typical procedure for the semihydrogenation of alkynes is as follows: alkyne $(0.14 \mathrm{mmol}), \mathrm{Au}$ catalyst $(2 \mathrm{~mol} \% \mathrm{Au})$, and $2 \mathrm{~mL}$ of solvent were placed in a modified Fischer-Porter $100 \mathrm{~mL}$ glass reactor. The reactor was purged five times with $\mathrm{H}_{2}$, leaving the vessel at 6 bar. The resulting mixture was vigorously stirred, and the temperature was maintained with an oil bath. After the desired time, the catalyst was removed by centrifugation, and the products were analyzed by GC with an internal standard to determine the conversion of alkyne and the selectivity for alkene. To determine the isolated yield of the obtained products, after the reaction was complete, the solvent was evaporated, and the crude reaction mixture was purified by column chromatography on silica gel to afford corresponding alkenes. ${ }^{1} \mathrm{H}$ confirmed the purity of the isolated products.

Computational Details. All calculations were performed at Density Functional Theory (DFT) level using the Vienna Abinitio Simulation Package (VASP). ${ }^{65,66}$ We use the PBE functional ${ }^{67}$ supplemented with Grimme's D2 dispersion scheme ${ }^{68}$ and refined parameters for transition metals. ${ }^{61}$ Core electrons were described by projector augmented wave (PAW) pseudopotentials ${ }^{69}$ and valence electrons by a kinetic energy cutoff of $450 \mathrm{eV}$. The $\mathrm{Au}(111)$ surface was modeled by a $(4 \times$ 4) supercell with four-layer thick slabs, where the two upper layers were relaxed and the two bottom ones were fixed to mimic the bulk. The Brillouin zone was sampled by a $3 \times 3 \times 1$ k-points mesh, generated through the Monkhorst-Pack method. ${ }^{70}$ To avoid spurious interactions between the periodic images, a vacuum region between the slabs of $15 \AA$ and dipole correction along $\mathrm{z}$ were included. ${ }^{71}$ Transition states were located with the climbing image nudged elastic band (CI-NEB) method. $^{72}$ The assessment of the minima and transition states was performed by diagonalizing the numerical Hessian matrix obtained by $\pm 0.015 \AA$ displacements. Metal and ligand atoms were fixed during frequency calculations. All inputs and final structures can be found in the ioChem-BD repository. ${ }^{73,74}$ 


\section{ASSOCIATED CONTENT}

\section{S Supporting Information}

Experimental details, additional experimental results, characterization of the catalyst (XRD, TEM, UV-vis), and $\mathrm{L} 1 / \mathrm{Au}$ adsorption energies (PDF)

\section{AUTHOR INFORMATION}

\section{Corresponding Author}

*E-mail for L.M.R.: lrossi@iq.usp.br.

ORCID $\odot$

Jhonatan Luiz Fiorio: 0000-0001-7435-7430

Renato Vitalino Gonçalves: 0000-0002-3372-6647

Manuel A. Ortuño: 0000-0002-6175-3941

Núria López: 0000-0001-9150-5941

Liane Marcia Rossi: 0000-0001-7679-0852

Notes

The authors declare no competing financial interest.

\section{ACKNOWLEDGMENTS}

The authors are grateful to the Brazilian government agencies FAPESP (Grant 2016/16738-7), CNPq, INCT-Catalise, and CAPES for financial support. We thank LNNano-CNPEM (Campinas, Brazil) for the use of the FEI Titan Themis 60-300 microscope and Brazilian Synchrotron Light Laboratory (LNLS) for use of its SXS experimental facilities (proposal SXS- 20170205). We thank MINECO (CTQ2015-68770) for financial support and BSC-RES for computational resources. M.A.O. also thanks the MINECO Juan de la CiervaIncorporación postdoctoral program (IJCI-2016-29762).

\section{REFERENCES}

(1) Trotus, I.-T.; Zimmermann, T.; Schüth, F. Catalytic Reactions of Acetylene: A Feedstock for the Chemical Industry Revisited. Chem. Rev. 2014, 114, 1761-1782.

(2) Sheldon, R. A.; van Bekkum, H. Fine Chemicals through Heterogeneous Catalysis; Wiley-VCH: Weinheim, 2001.

(3) Kyriakou, G.; Boucher, M. B.; Jewell, A. D.; Lewis, E. A.; Lawton, T. J.; Baber, A. E.; Tierney, H. L.; Flytzani-Stephanopoulos, M.; Sykes, E. C. H. Isolated Metal Atom Geometries as a Strategy for Selective Heterogeneous Hydrogenations. Science 2012, 335, 1209-1212.

(4) Teschner, D.; Borsodi, J.; Wootsch, A.; Revay, Z.; Havecker, M.; Knop-Gericke, A.; Jackson, S. D.; Schlogl, R. The Roles of Subsurface Carbon and Hydrogen in Palladium-Catalyzed Alkyne Hydrogenation. Science 2008, 320, 86-89.

(5) Zhao, Y.; Fu, G.; Zheng, N. Shaping the Selectivity in Heterogeneous Hydrogenation by Using MolecularModification Strategies: Experiment and Theory. Catal. Today 2017, 279, 36-44.

(6) Chen, T.; Rodionov, V. O. Controllable Catalysis with Nanoparticles: Bimetallic Alloy Systems and Surface Adsorbates. ACS Catal. 2016, 6, 4025-4033.

(7) López, N.; Vargas-Fuentes, C. Promoters in the Hydrogenation of Alkynes in Mixtures: Insights from Density Functional Theory. Chem. Commun. 2012, 48, 1379-1391.

(8) Vilé, G.; Albani, D.; Almora-Barrios, N.; López, N.; PérezRamírez, J. Advances in the Design of Nanostructured Catalysts for Selective Hydrogenation. Chem CatChem 2016, 8, 21-33.

(9) Mitsudome, T.; Kaneda, K. Gold Nanoparticle Catalysts for Selective Hydrogenations. Green Chem. 2013, 15, 2636.

(10) Stratakis, M.; Garcia, H. Catalysis by Supported Gold Nanoparticles: Beyond Aerobic Oxidative Processes. Chem. Rev. 2012, 112, 4469-4506.
(11) Segura, Y.; López, N.; Pérez-Ramírez, J. Origin of the Superior Hydrogenation Selectivity of Gold Nanoparticles in Alkyne + Alkene Mixtures: Triple- versus Double-Bond Activation. J. Catal. 2007, 247, 383-386.

(12) Shimizu, K.; Miyamoto, Y.; Kawasaki, T.; Tanji, T.; Tai, Y.; Satsuma, A. Chemoselective Hydrogenation of Nitroaromatics by Supported Gold Catalysts: Mechanistic Reasons of Size- and SupportDependent Activity and Selectivity. J. Phys. Chem. C 2009, 113, $17803-17810$

(13) Bus, E.; Miller, J. T.; van Bokhoven, J. A. Hydrogen Chemisorption on $\mathrm{Al}_{2} \mathrm{O}_{3}$-Supported Gold Catalysts. J. Phys. Chem. B 2005, 109, 14581-14587.

(14) Noujima, A.; Mitsudome, T.; Mizugaki, T.; Jitsukawa, K.; Kaneda, K. Selective Deoxygenation of Epoxides to Alkenes with Molecular Hydrogen Using a Hydrotalcite-Supported Gold Catalyst: A Concerted Effect between Gold Nanoparticles and Basic Sites on a Support. Angew. Chem., Int. Ed. 2011, 50, 2986-2989.

(15) Noujima, A.; Mitsudome, T.; Mizugaki, T.; Jitsukawa, K.; Kaneda, K. Unique Catalysis of Gold Nanoparticles in the Chemoselective Hydrogenolysis with $\mathrm{H}_{2}$ : Cooperative Effect between Small Gold Nanoparticles and a Basic Support. Chem. Commun. 2012, 48, 6723.

(16) Mitsudome, T.; Yamamoto, M.; Maeno, Z.; Mizugaki, T.; Jitsukawa, K.; Kaneda, K. One-step Synthesis of Core-Gold/ShellCeria Nanomaterial and Its Catalysis for Highly Selective Semihydrogenation of Alkynes. J. Am. Chem. Soc. 2015, 137, 13452-13455.

(17) Urayama, T.; Mitsudome, T.; Maeno, Z.; Mizugaki, T.; Jitsukawa, K.; Kaneda, K. Green, Multi-Gram One-Step Synthesis of Core-Shell Nanocomposites in Water and Their Catalytic Application to Chemoselective Hydrogenations. Chem. - Eur. J. 2016, 22, 1796217966.

(18) Albani, D.; Capdevila-Cortada, M.; Vilé, G.; Mitchell, S.; Martin, O.; López, N.; Pérez-Ramírez, J. Semihydrogenation of Acetylene on Indium Oxide: Proposed Single-Ensemble Catalysis. Angew. Chem., Int. Ed. 2017, 56, 10755-10760.

(19) Tejeda-Serrano, M.; Cabrero-Antonino, J. R.; Mainar-Ruiz, V.; López-Haro, M.; Hernández-Garrido, J. C.; Calvino, J. J.; Leyva-Pérez, A.; Corma, A. Synthesis of Supported Planar Iron Oxide Nanoparticles and Their Chemo- and Stereoselectivity for Hydrogenation of Alkynes. ACS Catal. 2017, 7, 3721-3729.

(20) Zhang, S.; Huang, Z.-Q.; Ma, Y.; Gao, W.; Li, J.; Cao, F.; Li, L.; Chang, C.-R.; Qu, Y. Solid Frustrated-Lewis-Pair Catalysts Constructed by Regulations on Surface Defects of Porous Nanorods of $\mathrm{CeO}_{2}$. Nat. Commun. 2017, 8, 15266 .

(21) Comas-Vives, A.; Ujaque, G. Unraveling the Pathway of Gold(I)-Catalyzed Olefin Hydrogenation: An Ionic Mechanism. J. Am. Chem. Soc. 2013, 135 (4), 1295-1305.

(22) Comas-Vives, A.; González-Arellano, C.; Corma, A.; Iglesias, M.; Sánchez, F.; Ujaque, G. Single-Site Homogeneous and Heterogeneized Gold(III) Hydrogenation Catalysts: Mechanistic Implications. J. Am. Chem. Soc. 2006, 128, 4756-4765.

(23) Campos, J. Dihydrogen and Acetylene Activation by a Gold(I)/ Platinum(0) Transition Metal Only Frustrated Lewis Pair. J. Am. Chem. Soc. 2017, 139, 2944-2947.

(24) Fiorio, J. L.; López, N.; Rossi, L. M. Gold-Ligand-Catalyzed Selective Hydrogenation of Alkynes into cis-Alkenes via $\mathrm{H}_{2}$ Heterolytic Activation by Frustrated Lewis Pairs. ACS Catal. 2017, 7, 2973-2980.

(25) Ren, D.; He, L.; Yu, L.; Ding, R.-S.; Liu, Y.-M.; Cao, Y.; He, H.Y.; Fan, K.-N. An Unusual Chemoselective Hydrogenation of Quinoline Compounds Using Supported Gold Catalysts. J. Am. Chem. Soc. 2012, 134, 17592-17598.

(26) Almora-Barrios, N.; Cano, I.; van Leeuwen, P. W. N. M.; López, N. Concerted Chemoselective Hydrogenation of Acrolein on Secondary Phosphine Oxide Decorated Gold Nanoparticles. ACS Catal. 2017, 7, 3949-3954.

(27) Cano, I.; Chapman, A. M.; Urakawa, A.; van Leeuwen, P. W. N. M. Air-Stable Gold Nanoparticles Ligated by Secondary Phosphine Oxides for the Chemoselective Hydrogenation of Aldehydes: Crucial Role of the Ligand. J. Am. Chem. Soc. 2014, 136, 2520-2528. 
(28) Cano, I.; Huertos, M. A.; Chapman, A. M.; Buntkowsky, G.; Gutmann, T.; Groszewicz, P. B.; van Leeuwen, P. W. N. M. Air-Stable Gold Nanoparticles Ligated by Secondary Phosphine Oxides as Catalyst for the Chemoselective Hydrogenation of Substituted Aldehydes: a Remarkable Ligand Effect. J. Am. Chem. Soc. 2015, 137 (24), 7718-7727.

(29) Li, G.; Abroshan, H.; Chen, Y.; Jin, R.; Kim, H. J. Experimental and Mechanistic Understanding of Aldehyde Hydrogenation using Au25 Nanoclusters with Lewis Acids: Unique sites for Catalytic Reactions. J. Am. Chem. Soc. 2015, 137, 14295-14304.

(30) Lu, G.; Zhang, P.; Sun, D.; Wang, L.; Zhou, K.; Wang, Z.-X.; Guo, G.-C. Gold Catalyzed Hydrogenations of Small Imines and Nitriles: Enhanced Reactivity of $\mathrm{Au}$ Surface toward $\mathrm{H}_{2}$ via Collaboration with a Lewis Base. Chem. Sci. 2014, 5, 1082-1090.

(31) Welch, G. C.; Juan, R. R. S.; Masuda, J. D.; Stephan, D. W. Reversible, Metal-Free Hydrogen Activation. Science 2006, 314, 11241126.

(32) Stephan, D. W. The Broadening Reach of Frustrated Lewis Pair Chemistry. Science 2016, 354, aaf7229.

(33) Stephan, D. W. Frustrated Lewis Pairs. J. Am. Chem. Soc. 2015, 137, 10018-10032.

(34) Ghuman, K. K.; Wood, T. E.; Hoch, L. B.; Mims, C. A.; Ozin, G. A.; Singh, C. V. Illuminating $\mathrm{CO}_{2}$ Reduction on Frustrated Lewis Pair Surfaces: Investigating the Role of Surface Hydroxides and Oxygen Vacancies onNanocrystalline $\operatorname{In}_{2} \mathrm{O}_{3-x}(\mathrm{OH})_{y}$. Phys. Chem. Chem. Phys. 2015, 17, 14623-14635.

(35) Ghuman, K. K.; Hoch, L. B.; Szymanski, P.; Loh, J. Y. Y.; Kherani, N. P.; El-Sayed, M. A.; Ozin, G. A.; Singh, C. V. Photoexcited Surface Frustrated Lewis Pairs for Heterogeneous Photocatalytic $\mathrm{CO}_{2}$ Reduction. J. Am. Chem. Soc. 2016, 138, 1206-1214.

(36) Westerhaus, F. A.; Jagadeesh, R. V.; Wienhöfer, G.; Pohl, M.-M.; Radnik, J.; Surkus, A.-E.; Rabeah, J.; Junge, K.; Junge, H.; Nielsen, M.; Brückner, A.; Beller, M. Heterogenized Cobalt Oxide Catalysts for Nitroarene Reduction by Pyrolysis of Molecularly Defined Complexes. Nat. Chem. 2013, 5, 537-543.

(37) Liu, W.; Zhang, L.; Yan, W.; Liu, X.; Yang, X.; Miao, S.; Wang, W.; Wang, A.; Zhang, T. Single-atom Dispersed Co-N-C Catalyst: Structure Identification and Performance for Hydrogenative Coupling of Nitroarenes. Chem. Sci. 2016, 7, 5758-5764.

(38) Pisiewicz, S.; Formenti, D.; Surkus, A.-E.; Pohl, M.-M.; Radnik, J.; Junge, K.; Topf, C.; Bachmann, S.; Scalone, M.; Beller, M. Synthesis of Nickel Nanoparticles with N-Doped Graphene Shells for Catalytic Reduction Reactions. ChemCatChem 2016, 8, 129-134.

(39) Bi, Q.-Y.; Lin, J.-D.; Liu, Y.-M.; He, H.-Y.; Huang, F.-Q.; Cao, Y. Dehydrogenation of Formic Acid at Room Temperature: Boosting Palladium Nanoparticle Efficiency by Coupling with PyridinicNitrogen-Doped Carbon. Angew. Chem., Int. Ed. 2016, 55, 1184911853.

(40) Chen, Z.; Mitchell, S.; Vorobyeva, E.; Leary, R. K.; Hauert, R.; Furnival, T.; Ramasse, Q. M.; Thomas, J. M.; Midgley, P. A.; Dontsova, D.; Antonietti, M.; Pogodin, S.; López, N.; Pérez-Ramírez, J. Stabilization of Single Metal Atoms on Graphitic Carbon Nitride. Adv. Funct. Mater. 2017, 27, 1605785.

(41) Cui, X.; Surkus, A.-E.; Junge, K.; Topf, C.; Radnik, J.; Kreyenschulte, C.; Beller, M. Highly Selective Hydrogenation of Arenes using Nanostructured Ruthenium Catalysts Modified with a Narbon-Nitrogen Matrix. Nat. Commun. 2016, 7, 11326.

(42) Jagadeesh, R. V.; Surkus, A.-E.; Junge, H.; Pohl, M.-M.; Radnik, J.; Rabeah, J.; Huan, H.; Schunemann, V.; Bruckner, A.; Beller, M. Nanoscale $\mathrm{Fe}_{2} \mathrm{O}_{3}$-Based Catalysts for Selective Hydrogenation of Nitroarenes to Anilines. Science 2013, 342, 1073-1076.

(43) Liu, W.; Zhang, L.; Liu, X.; Liu, X.; Yang, X.; Miao, S.; Wang, W.; Wang, A.; Zhang, T. Discriminating Catalytically Active FeN $_{x}$ Species of Atomically Dispersed $\mathrm{Fe}-\mathrm{N}-\mathrm{C}$ Catalyst for Selective Oxidation of the C-H Bond. J. Am. Chem. Soc. 2017, 139, 1079010798.

(44) He, L.; Weniger, F.; Neumann, H.; Beller, M. Synthesis, Characterization, and Application of Metal Nanoparticles Supported on Nitrogen-Doped Carbon: Catalysis beyond Electrochemistry. Angew. Chem., Int. Ed. 2016, 55, 12582-12594.

(45) Cao, Y.; Mao, S.; Li, M.; Chen, Y.; Wang, Y. Metal/Porous Carbon Composites for Heterogeneous Catalysis: Old Catalysts with Improved Performance Promoted by N-Doping. ACS Catal. 2017, 7, 8090-8112.

(46) Chen, F.; Topf, C.; Radnik, J.; Kreyenschulte, C.; Lund, H.; Schneider, M.; Surkus, A.-E.; He, L.; Junge, K.; Beller, M. Stable and Inert Cobalt Catalysts for Highly Selective and Practical Hydrogenation of $\mathrm{C} \equiv \mathrm{N}$ and $\mathrm{C}=\mathrm{O}$ Bonds. J. Am. Chem. Soc. 2016, 138, 8781-8788

(47) Chen, F.; Surkus, A.-E.; He, L.; Pohl, M.-M.; Radnik, J.; Topf, C.; Junge, K.; Beller, M. Selective Catalytic Hydrogenation of Heteroarenes with $\mathrm{N}$-Graphene-Modified Cobalt Nanoparticles $\left(\mathrm{Co}_{3} \mathrm{O}_{4}-\mathrm{Co} / \mathrm{NGr} @ \alpha-\mathrm{Al}_{2} \mathrm{O}_{3}\right)$. J. Am. Chem. Soc. 2015, 137, 1171811724 .

(48) Vilé, G.; Albani, D.; Nachtegaal, M.; Chen, Z.; Dontsova, D.; Antonietti, M.; López, N.; Pérez-Ramírez, J. A Stable Single-Site Palladium Catalyst for Hydrogenations. Angew. Chem., Int. Ed. 2015, 54, 11265-11269.

(49) Formenti, D.; Ferretti, F.; Topf, C.; Surkus, A.-E.; Pohl, M.-M.; Radnik, J.; Schneider, M.; Junge, K.; Beller, M.; Ragaini, F. Co-Based Heterogeneous Catalysts from Well-Defined $\alpha$-Diimine Complexes: Discussing the Role of Nitrogen. J. Catal. 2017, 351, 79-89.

(50) Chen, Z.; Pronkin, S.; Fellinger, T.-P.; Kailasam, K.; Vilé, G.; Albani, D.; Krumeich, F.; Leary, R.; Barnard, J.; Thomas, J. M.; PérezRamírez, J.; Antonietti, M.; Dontsova, D. Merging Single-AtomDispersed Silver and Carbon Nitride to a Joint Electronic System via Copolymerization with Silver Tricyanomethanide. ACS Nano 2016, 10, 3166-3175.

(51) Jagadeesh, R. V.; Stemmler, T.; Surkus, A. E.; Bauer, M.; Pohl, M. M.; Radnik, J.; Junge, K.; Junge, H.; Bruckner, A.; Beller, M. Cobalt-Based Nanocatalysts for Green Oxidation and Hydrogenation Processes. Nat. Protoc. 2015, 10, 916-926.

(52) Jagadeesh, R. V.; Stemmler, T.; Surkus, A.-E.; Junge, H.; Junge, K.; Beller, M. Hydrogenation using Iron Oxide - Based Nanocatalysts for the Synthesis of Amines. Nat. Protoc. 2015, 10, 548-557.

(53) Wang, L.; Wang, H.; Rice, A. E.; Zhang, W.; Li, X.; Chen, M.; Meng, X.; Lewis, J. P.; Xiao, F.-S. Design and Preparation of Supported $\mathrm{Au}$ Catalyst with Enhanced Catalytic Activities by Rationally Positioning Au Nanoparticles on Anatase. J. Phys. Chem. Lett. 2015, $6,2345-2349$.

(54) Zhan, W.; He, Q.; Liu, X.; Guo, Y.; Wang, Y.; Wang, L.; Guo, Y.; Borisevich, A. Y.; Zhang, J.; Lu, G.; Dai, S. A Sacrificial Coating Strategy Toward Enhancement of Metal-Support Interaction for Ultrastable Au Nanocatalysts. J. Am. Chem. Soc. 2016, 138, 1613016139.

(55) Duan, J.; Chen, S.; Jaroniec, M.; Qiao, S. Z. Heteroatom-Doped Graphene-Based Materials for Energy-Relevant Electrocatalytic Processes. ACS Catal. 2015, 5, 5207-5234.

(56) Guo, D.; Shibuya, R.; Akiba, C.; Saji, S.; Kondo, T.; Nakamura, J. Active Sites of Nitrogen-Doped Carbon Materials for Oxygen Reduction Reaction Clarified using Model Catalysts. Science 2016, 351, $361-365$.

(57) Sun, X.; Li, B.; Liu, T.; Song, J.; Su, D. S. Designing Graphene as a New Frustrated Lewis Pair Catalyst for Hydrogen Activation by CoDoping. Phys. Chem. Chem. Phys. 2016, 18, 11120-11124.

(58) Gu, J.; Du, Q.; Han, Y.; He, Z.; Li, W.; Zhang, J. NitrogenDoped Carbon Supports with Terminated Hydrogen andTheir Effects on Active Gold Species: a Density Functional Study. Phys. Chem. Chem. Phys. 2014, 16, 25498-25507.

(59) Zhan, W.; Shu, Y.; Sheng, Y.; Zhu, H.; Guo, Y.; Wang, L.; Guo, Y.; Zhang, J.; Lu, G.; Dai, S. Surfactant-Assisted Stabilization of Au Colloids on Solids for Heterogeneous Catalysis. Angew. Chem., Int. Ed. 2017, 56, 4494-4498.

(60) Syomin, D.; Kim, J.; Koel, B. E.; Ellison, G. B. Identification of Adsorbed Phenyl $\left(\mathrm{C}_{6} \mathrm{H}_{5}\right)$ Groups on Metal Surfaces: Electron-Induced Dissociation of Benzene on $\mathrm{Au}(111)$. J. Phys. Chem. B 2001, 105, 8387-8394. 
(61) Almora-Barrios, N.; Carchini, G.; Błoński, P.; López, N. Costless Derivation of Dispersion Coefficients for Metal Surfaces. J. Chem. Theory Comput. 2014, 10, 5002-5009.

(62) Arndt, S.; Rudolph, M.; Hashmi, A. S. K. Gold-Based Frustrated Lewis Acid/Base Pairs (FLPs). Gold Bull. 2017, 50, 267-282.

(63) Stephan, D. W. Gold-Based Frustrated Lewis Acid/Base Pairs (FLPs). Acc. Chem. Res. 2015, 48, 306-316.

(64) Chapman, A. M.; Haddow, M. F.; Wass, D. F. Frustrated Lewis Pairs beyond the Main Group: Synthesis, Reactivity, and Small Molecule Activation with Cationic Zirconocene-Phosphinoaryloxide Complexes. J. Am. Chem. Soc. 2011, 133, 18463-18478.

(65) Kresse, G.; Hafner, J. Ab Initio Molecular Dynamics for Liquid Metals. Phys. Rev. B: Condens. Matter Mater. Phys. 1993, 47, 558-561.

(66) Kresse, G.; Furthmüller, J. Efficiency of Ab-Initio Total Energy Calculations for Metals and Semiconductors using a Plane-Wave Basis Set. Comput. Mater. Sci. 1996, 6, 15-50.

(67) Perdew, J. P.; Burke, K.; Ernzerhof, M. Generalized Gradient Approximation Made Simple. Phys. Rev. Lett. 1996, 77, 3865-3868.

(68) Grimme, S. J. Semiempirical GGA-Type Density Functional Constructed with a Long-Range DispersionCorrection. J. Comput. Chem. 2006, 27, 1787-1799.

(69) Kresse, G.; Joubert, D. From Ultrasoft Pseudopotentials to the Projector Augmented-Wave Method. Phys. Rev. B: Condens. Matter Mater. Phys. 1999, 59, 1758-1775.

(70) Monkhorst, H. J.; Pack, J. D. Special Points for Brillouin-Zone Integrations. Phys. Rev. B 1976, 13, 5188-5192.

(71) Makov, G.; Payne, M. C. Periodic Boundary Conditions in ab initio Calculations. Phys. Rev. B: Condens. Matter Mater. Phys. 1995, 51, 4014-4022.

(72) Henkelman, G.; Jónsson, H. Improved Tangent Estimate in the Nudged Elastic Band Method for Finding Minimum Energy Paths and Saddle Points. J. Chem. Phys. 2000, 113, 9978-9985.

(73) Álvarez-Moreno, M.; de Graaf, C.; López, N.; Maseras, F.; Poblet, J. M.; Bo, C. Managing the Computational Chemistry Big Data Problem: The ioChem-BD Platform. J. Chem. Inf. Model. 2015, 55, $95-103$.

(74) Ortuño, M. A.Au-NC Collection Home Page. DOI: 10.19061/ iochem-bd-1-66. 